\title{
Effects of Two Trichoderma Strains on Plant Growth, Rhizosphere Soil Nutrients, and Fungal Community of Pinus sylvestris var. mongolica Annual Seedlings
}

\author{
Saiyaremu Halifu ${ }^{1}$, Xun Deng ${ }^{2}$, Xiaoshuang Song ${ }^{2}$ and Ruiqing Song ${ }^{1, *}$ \\ 1 College of Forestry, Northeast Forestry University, Harbin 150040, China \\ 2 Institute of Forestry Protection, Heilongjiang Forestry Academy, Harbin 150040, China \\ * Correspondence: songrq1964@nefu.edu.cn; Tel.: +86-13804522836
}

Received: 16 June 2019; Accepted: 25 August 2019; Published: 2 September 2019

check for updates

\begin{abstract}
Trichoderma spp. are proposed as major plant growth-promoting fungi that widely exist in the natural environment. These strains have the abilities of rapid growth and reproduction and efficient transformation of soil nutrients. Moreover, they can change the plant rhizosphere soil environment and promote plant growth. Pinus sylvestris var. mongolica has the characteristics of strong drought resistance and fast growth and plays an important role in ecological construction and environmental restoration. The effects on the growth of annual seedlings, root structure, rhizosphere soil nutrients, enzyme activity, and fungal community structure of $P$. sylvestris var. mongolica were studied after inoculation with Trichoderma harzianum E15 and Trichoderma virens ZT05, separately. The results showed that after inoculation with T. harzianum E15 and T. virens ZT05, seedling biomass, root structure index, soil nutrients, and soil enzyme activity were significantly increased compared with the control $(p<0.05)$. There were significant differences in the effects of T. harzianum E15 and T. virens ZT05 inoculation on the growth and rhizosphere soil nutrient of P. sylvestris var. mongolica $(p<0.05)$. For the E15 treatment, the seedling height, ground diameter, and total biomass of seedlings were higher than that those of the ZT05 treatment, and the rhizosphere soil nutrient content and enzyme activity of the ZT05 treatment were higher than that of the E15 treatment. The results of alpha and beta diversity analyses showed that the fungi community structure of rhizosphere soil was significantly different $(p<0.05)$ among the three treatments (inoculated with T. harzianum E15, T. virens ZT05, and not inoculated with Trichoderma). Overall, Trichoderma inoculation was correlated with the change of rhizosphere soil nutrient content.
\end{abstract}

Keywords: Trichoderma spp.; growth promotion; Pinus sylvestris var. mongolica; soil microecological environment; high-throughput sequencing

\section{Introduction}

Trichoderma species belong to Hyphomyceteales, Hyphomycetes, Deuteromycotina, and Eumycota. Their existence in the natural ecological environment is widespread; for example, they are found in plant seeds, the rhizosphere, the phyllosphere, corms, and soils. These species have plant growth promotion and soil environment improvement abilities [1,2]. During the colonization in plant roots, the mycelia of Trichoderma fungi twine around the plant roots to form an appressorium-like structure, then penetrate the root epidermis layer and survive for a long time between the plant cells of the epidermis and the cortex [3], having a direct promotional effect on the growth of seedlings [4-6], nutrient uptake in the rhizosphere [7-10], and rhizosphere microbial community structure improvement [11-14]. Chang and Baler [15] treated seeds or roots of pepper, Vinca, chrysanthemum, tomato, and cucumber with a conidia suspension of Trichoderma harzianum T-203 and found that the germination rate of pepper 
increased, the flowering period of Vinca came earlier, the number of chrysanthemum flowers increased, the plant height and fresh weight of all these plants increased. Furthermore, the dry weight of tomato, cucumber, and pepper fruits also increased significantly. During the interaction among Trichoderma harzianum, Trichoderma virens, and Arabidopsis thaliana, the contents of the JA (jasmonic acid) and (salicylic acid) SA and the number of lateral roots were all significantly increased [16,17].

Many nutrients in the soil exist in a sparingly soluble or insoluble state, which affects the circulation of nutrients in the soil to some extent. Trichoderma species promote nutrient uptake by secreting organic acids to dissolve minerals and activate nutrients in the soil, leading to the circulation and utilization of nutrients in the soil. At the same time, due to the strong colonization ability of Trichoderma species, they expand the contact area between the rhizosphere and soil and increase the secretion of extracellular enzymes such as sucrase, urease, and phosphatase, as well as organic acids in the rhizosphere to improve nutrient cycling and enzyme activity in the soil. Maeda [18] reported that Trichoderma species can decompose nitrogen compounds into available nitrogen and release less $\mathrm{NO}_{2}$. Khan [19] and Harman [20] found that Trichoderma species convert nutrients into effective nutrients to increase soil nutrient circulation in the soil, enabling the reduction of the use of nitrogen fertilizer. Mbarki [21] found that Trichoderma inoculation increased the effective nutrient content and the soil enzyme activity to repair soil and promote plant growth. The imbalance of the soil microbial community structure is the main cause of soil-borne diseases, and its diversity is an important indicator to measure soil properties. Due to their advantages of fast growth and strong vitality, Trichoderma species rapidly occupy the growth space and absorb the nutrients needed. The Trichoderma genus also has the feature of hyperparasitism; it secretes cell wall-degrading enzymes such as chitinases, cellulases, xylanases, glucanases, and proteinases. Trichoderma species absorb nutrients through degrading soil microbial cells, leading to the change of the soil microbial community structure [22,23]. Wagner [24] and Yadav [25] found that Trichoderma inoculation increases nutrient content and microbial biomass in addition to improving the soil microbial community structure.

Mongolian pine (Pinus sylvestris var. mongolica), a geographical variety of Scots pine (P. sylvestris), is naturally distributed in the Daxinganling mountains of China $\left(50^{\circ} 10^{\prime}-53^{\circ} 33^{\prime} \mathrm{N}, 121^{\circ} 11^{\prime}-127^{\circ} 10^{\prime} \mathrm{E}\right)$, in Honghuaerji of the Hulunbeier sandy plains of China $\left(47^{\circ} 35^{\prime}-48^{\circ} 36^{\prime} \mathrm{N}, 118^{\circ} 58^{\prime}-120^{\circ} 32^{\prime} \mathrm{E}\right)$, and in parts of Russia and Mongolia $\left(46^{\circ} 30^{\prime}-53^{\circ} 59^{\prime} \mathrm{N}, 118^{\circ} 00^{\prime}-130^{\circ} 08^{\prime} \mathrm{E}\right)$ [26]. It is often planted as an ornamental tree because of its height and greening characteristics. In addition, this tree is characterized by cold hardiness, drought tolerance, strong adaptability, and rapid growth [27,28]. It is currently the main coniferous tree species utilized in the "3-North Shelter Forest Program" and the "Sand-Control Project" in China, and plays an important role in ecological construction and environmental restoration.

The excessive and uncontrolled use of chemical fertilizers and pesticides have resulted in various adverse effects such as serious diseases, soil environmental damage, and poor growth of seedlings [29]. The utilization of beneficial microorganisms, including Trichoderma spp. and microbial metabolites, is a new environmentally friendly plant health management method compared with the use of chemical pesticides. This approach has the advantages of being pollution-free, residue-free, safe for natural enemies, difficult to produce resistance, and conducive to human and animal safety, as well as the advantage of environmental protection [30,31].

In this study, T. harzianum E15 (introduced from the University of Edinburgh, UK) and T. virens ZT05 (isolated from the Zhanggutai Experimental Forest Farm of Liaoning Province, China) were used to study the effects of Trichoderma spp. on the growth and root structure of annual seedlings of P. sylvestris var. mongolica, on the physical and chemical properties of rhizosphere soil, and on the fungi community structure. A comparison was made of effects of the introduced and local isolates of Trichoderma strains on seedling growth and the soil environment. The research objectives include the assessment of the effects of (1) T. harzianum strain E15 and T. virens strain ZT05 on annual seedling growth and root structure of P. sylvestris var. mongolica; (2) T. harzianum strain E15 and T. virens strain ZT05 on rhizosphere soil physicochemical properties and enzyme activities, which in turn affect the annual seedlings of P. sylvestris var. mongolica; and (3) T. harzianum strain E15 and T. virens strain ZT05 
on the fungi community structure annual in the rhizosphere soil in which the P. sylvestris var. Mongolica seedlings were planted.

\section{Materials and Methods}

\subsection{Organisms and Growth Conditions}

Two Trichoderma strains were used in this research. T. harzianum E15 was introduced from the University of Edinburgh, UK to China. T. virens ZT05 was isolated from the rhizosphere soil of the P. sylvestris var. mongolica forest of the Zhanggutai Experimental Forest Farm of Liaoning Province $\left(42^{\circ} 43^{\prime}-42^{\circ} 51^{\prime} \mathrm{N}, 121^{\circ} 53^{\prime}-122^{\circ} 22^{\prime} \mathrm{E}\right)$, China. These two strains were grown on a PDA medium (potato extract $12 \mathrm{~g} / \mathrm{L}$, dextrose $20 \mathrm{~g} / \mathrm{L}$, agar $14 \mathrm{~g} / \mathrm{L}$; Haibo Biotechnology, China) at $\mathrm{pH}$ 6.0. The Trichoderma species on PDA medium was cut with a sterile puncher $(\varnothing=5 \mathrm{~mm})$ after culturing for 5 days. Suspension cultures of the two Trichoderma strains were obtained by transferring the mycelium inoculum to liquid PD medium (PDA medium without agar) separately. Seven-day suspension cultures, maintained in the dark at $25^{\circ} \mathrm{C}$ under agitation (150 rpm), were used to inoculate the seedlings [32].

The experiment seeds of P. sylvestris var. mongolica (purchased from the Zhanggutai Experimental Forest Farm in Zhangwu County, Liaoning Province, China) were surface-sterilized with potassium permanganate $(0.5 \%, \mathrm{v} / \mathrm{v})$ for $30 \mathrm{~min}$, then washed five times with sterile distilled water. They were then germinated on sterile moistened gauze at $25^{\circ} \mathrm{C}$ for 5 days. After germination, the seedlings were transferred to plastic pot $(15 \times 15 \mathrm{~cm}, 20$ seeds per pot) filled with a sterile culture substrate-namely, a peat soil/vermiculite/sand $(2: 1: 1, \mathrm{v} / \mathrm{v} / \mathrm{v})$ mixture that was sterilized in a high-temperature autoclave for $2 \mathrm{~h}$ at $121^{\circ} \mathrm{C}$. The pots were kept under greenhouse conditions (day/night thermal regime of $22 / 30 \pm 3^{\circ} \mathrm{C}$, and $14 \mathrm{~h}$ light/10 h dark photoperiod) and watered every 2 days for 1 month, after which the seedlings were inoculated with the fungi $[33,34]$.

\subsection{Experimental Design and Seedling Inoculation}

For all treatments, including the control, 20 pots ( 20 seedlings per pot) were prepared, giving a total of 400 seedlings per treatment. There were three treatments: (1) inoculation with PD blank culture medium (CK); (2) single inoculation with T. virens ZT05; and (3) single inoculation with T. harzianum E15. The inoculations were performed by transferring $100 \mathrm{~mL}$ of the fungal suspension culture into the planting hole [35], where it was introduced at the root system level. The control plants were inoculated with $100 \mathrm{~mL}$ PD blank culture medium. All treatments were arranged at random under the greenhouse conditions given above.

\subsection{Sampling and Analysis of Seedlings}

The seedlings were harvested 3 months after inoculation. The harvest was conducted without damaging the root system, which was carefully washed to remove the soil. A total of 50 seedlings per treatment were randomly selected, the first 30 seedling were used to measure the biomass index. For each seedling, the biomass index included calculations of the plant height, ground diameter, fresh weight, and dry weight at harvest. Once the fresh weight had been measured, the seedlings were oven-dried at $85^{\circ} \mathrm{C}$ for $5 \mathrm{~h}$ to measure the dry weight.

\subsection{Soil Properties Analysis}

Soil samples were collected from 100 randomly selected seedlings per treatment. Rhizosphere soil samples were collected from the root zone within $5 \mathrm{~mm}$ using a brush and passed through $1 \mathrm{~mm}$ mesh screen. Soil samples used to determine the enzyme activity and physicochemical properties were air-dried at $25^{\circ} \mathrm{C}$ and collected into sterile sample bags, then kept in a $5{ }^{\circ} \mathrm{C}$ refrigerator until further assays.

Organic matter $(\mathrm{OM})$ was measured using the potassium dichromate oxidation heating method [36]. Total nitrogen (TN) was determined using the Kjeldahl method [36], total phosphorus (TP) was 
determined using Mo-Sb colorimetry [36], available phosphorus (AP) was determined using the antimony bismuth anti-colorimetric method with double acid leaching, rapidly available potassium (AK) was measured using a NH4OAc leaching flame photometer [36], and total potassium was determined using aflame photometer [36]. A pH meter [36] was used to determine soil pH (1:2.5). The soil saccharase, catalase, acid phosphatase, and urease activities were measured using a kit from Nanjing.

\subsection{Fungal Diversity Analysis}

The rhizosphere soil samples collected according to the method described above and $5.0 \mathrm{~g}$ soil samples per biological repetition were placed in $50 \mathrm{~mL}$ sterile centrifugal tube and transported to the laboratory in a cooler with an icepack. Soil samples used for high-throughput sequencing were stored in a centrifuge tube at $-80{ }^{\circ} \mathrm{C}$ [37-39] until soil DNA extraction. For the high-throughput sequencing of soil microorganisms, the total genomic DNA was extracted from $0.5 \mathrm{~g}$ of soil using an EZNA Soil DNA Kit (Omega Bio-Tek, Norcross, GA, USA) according to the manufacturer's instructions. DNA was eluted with $100 \mu \mathrm{L}$ of elution solution from the kit. The DNA sample concentration and quality (A260/A280 ratio) were measured using a NanoDrop2000 spectrophotometer (Thermo Scientific, Walthan, MA, United States). Each treatment had three replicates in our experiment. High-throughput sequencing analysis of the ITS region was performed to determine soil fungal communities. For each treatment, three replicates were sequenced. The primers ITS1 (5'-CTTGGTCATTTAGAGGAAGTAA- $3^{\prime}$ ) and ITS2 (5'-GCTGCGTTCTTCATCGATGC-3') were used to amplify the ITS1 region of the fungal ITS [10-13]. PCR was performed in a $20 \mu \mathrm{L}$ reaction system: $4 \mu \mathrm{L}$ of $5 \times$ FastPfu buffer, $2 \mu \mathrm{L}$ of $2.5 \mathrm{~m}$ MdNTPs, $0.8 \mu \mathrm{L}$ of each primer $(5 \mu \mathrm{M}), 0.4 \mu \mathrm{L}$ of FastPfu polymerase, $0.2 \mu \mathrm{L}$ of BSA, $10 \mathrm{ng}$ of template DNA, and $11.6 \mu \mathrm{L}$ of double-distilled water [37,38]. The PCR conditions were as follows: $95{ }^{\circ} \mathrm{C}$ for $3 \mathrm{~min}, 27 \mathrm{cycles}$ of $30 \mathrm{~s}$ at $95{ }^{\circ} \mathrm{C}, 30 \mathrm{~s}$ at $55^{\circ} \mathrm{C}$, and $30 \mathrm{~s}$ at $72{ }^{\circ} \mathrm{C}$, and with a final extension of $10 \mathrm{~min}$ at $72{ }^{\circ} \mathrm{C}$. After PCR amplification, the obtained products were purified using an AxyPrep DNA Gel Extraction Kit (Axygen Biosciences, Union City, CA, USA) and quantified with QuantiFluor-ST (Promega, USA). Then, the purified amplicons were pooled in equimolar concentrations as a single aliquot and employed for library construction, and sequencing was performed on an Illumina MiSeq sequencer at Majorbio Biotechnology Co., Ltd. (Shanghai, China). Trimmomatic and FLASH software were employed to quality-filter and merge raw fastqfu files [39], while UPARSE software (version 7.1, http://drive5.com/uparse/) was employed to further analyze the pyrosequencing data. The sequences were then divided into operational taxonomic units (OTUs) with a $97 \%$ similarity cutoff, after which chimeras were removed using UCHIME [40,41]. RDP Classifier (http://rdp.cme.msu.edu/) was employed for the taxonomic annotation of each sequence within the confidence threshold of 0.7.

\subsection{Data Analyses}

Excel 2013 software was used for data processing. The differences of plant biomass, root structure index, soil $\mathrm{pH}$, chemical properties, and soil enzymes were determined by one-way analysis of variance (ANOVA) in IBM SPSS 22.0 (IBM Corporation, New York, NY, USA). In addition, Pearson's method was performed for correlation analysis [37]. The differences were considered statistically significant at a 0.05 probability level in this study. Mothur software [42] was employed to analyze the alpha diversity index and rarefaction, and the coverage index was used to represent the sequencing depth index. The Ace (https://www.mothur.org/wiki/Ace) and Chao1 (https:/www.mothur.org/wiki/Chao) indexes were used to represent the community abundance, while the Shannon (https://www.mothur.org/wiki/Shannon) and Simpson (https://www.mothur.org/wiki/Simpson) indexes were used to represent the species richness and diversity of the fungal community $[43,44]$. Additionally, the similarities analysis (ANOSIM) and heatmap analysis were calculated in the vegan package of $R$ language $[45,46]$ and the Unifrac distance calculation was performed for fungal beta diversity comparisons. The figures were generated using Origin 2019b (Origin Lab Corporation, Northampton, MA, USA). 


\section{Results and Analysis}

\subsection{Effects of Trichoderma Inoculation on Seedling Growth}

\subsubsection{Seedling Height}

Trichoderma inoculation promoted the growth of seedlings, as indicated by the significantly different heights between the control and treated groups $(p<0.05)$ (Figure 1). Specifically, the seedling height of the groups treated with ZT05 and E15 increased by $18.89 \%$ and $27.63 \%$, respectively, relative to the control. Additionally, the height of seedlings treated with E15 was $7.35 \%$ greater than the height of those treated with ZT05.
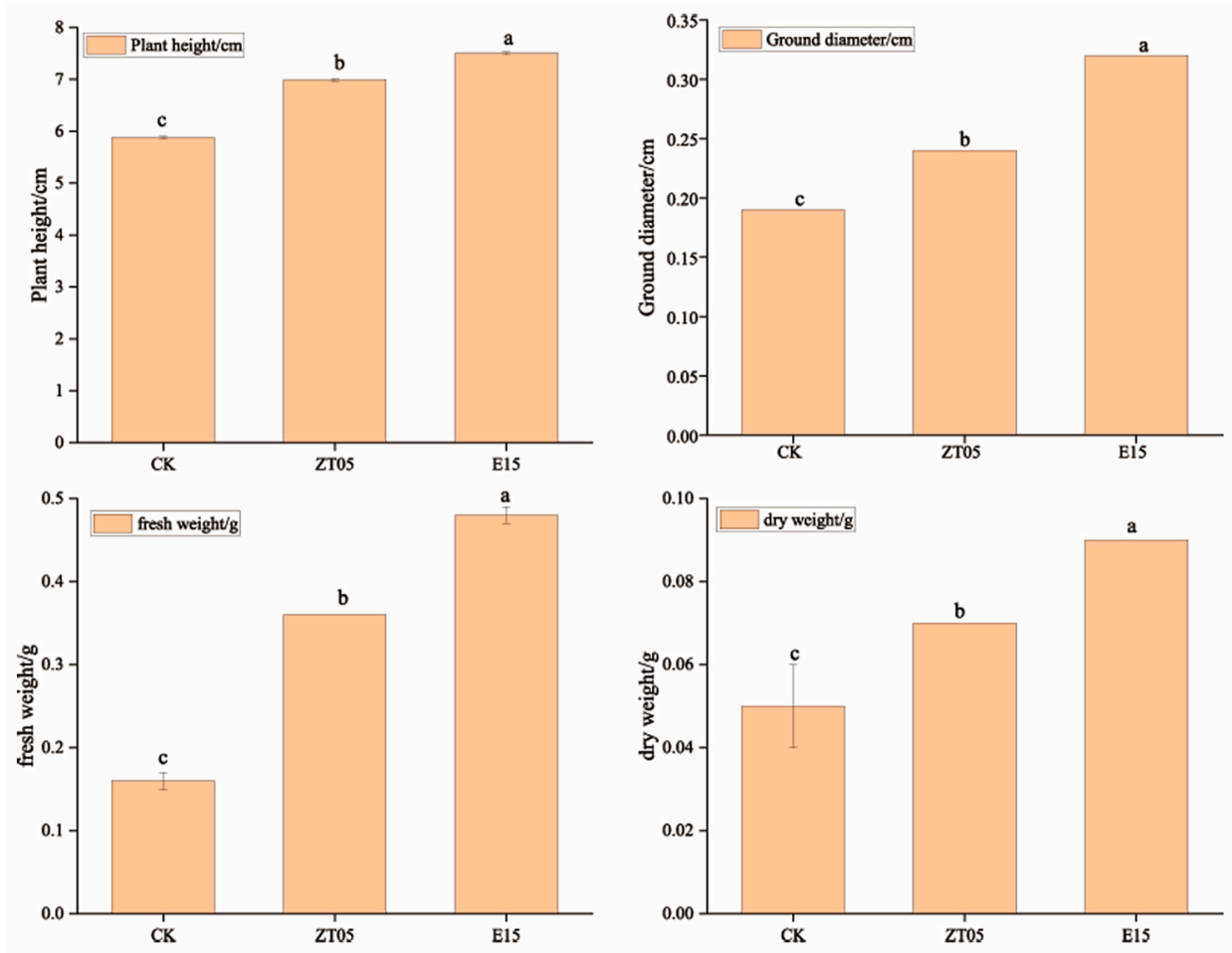

Figure 1. Effects of Trichoderma inoculation on plant growth. CK: inoculation with PD blank culture medium. ZT05: single inoculation with T. virens ZT05. E15: single inoculation with T. harzianum E15. Different letters indicate significant difference at $p<0.05$, according to Duncan's new multiple range test. Vertical bars indicate standard error (SE).

\subsubsection{Seedling Diameter}

As shown in Figure 1, the diameters of seedlings in the ZT05 and E15 treatment groups increased by $27.50 \%$ and $68.50 \%$, respectively, relative to the control. Moreover, the E15 treatment group exhibited diameters increased $32.16 \%$ more than the ZT05 treatment group.

\subsubsection{Seedling Biomass}

Trichoderma inoculation increased seedling biomass (Figure 1). The fresh weight of seedlings inoculated with ZT05 and E15 increased by $125.00 \%$ and $200.00 \%$, respectively, compared to the control, and the seedling fresh weight of the E15 treatment group increased 33.33\% more compared to the ZT05 treatment group. The dry weight of seedlings inoculated with ZT05 and E15 increased by $28.57 \%$ and $44.44 \%$, respectively, compared to the control, and the seedling dry weight of the E15 treatment group increased $22.22 \%$ more compared to the ZT05 treatment group. 


\subsection{Effect of Trichoderma Inoculation on the Root Structure of Seedlings}

Root length and surface area are important parameters for measuring the distribution of roots, while root average diameter, tip number, and branch number are important parameters for measuring root absorption efficiency. As shown in Table 1 and Figure 2, Trichoderma inoculation significantly increased root system parameters such as root length, root surface area, average root diameter, and number of root tips and branches $(p<0.05)$. When compared with the control, treatment with ZT05 increased root length by $25.11 \%$, root surface area by $98.19 \%$, average root diameter by $5.66 \%$, root tip number by $45.89 \%$ and branch number by $74.42 \%$. When compared with the control, treatment with E15 increased these parameters by $3.43 \%, 18.21 \%, 3.77 \%, 22.10 \%$, and $31.40 \%$, respectively. When compared with treatment with E15, these indexes were $20.96 \%, 67.66 \%, 1.82 \%, 19.48 \%$, and $32.74 \%$ higher, respectively, following treatment with ZT05.

Table 1. Effects of Trichoderma inoculation on seedling root structure. CK: inoculation with PD blank culture medium. ZT05: single inoculation with T. virens ZT05. E15: single inoculation with T. harzianum E15. Different letters in the columns indicate significant differences $(p<0.05)$, according to Duncan's new multiple range test.

\begin{tabular}{|c|c|c|c|}
\hline Index & CK & ZT05 & E15 \\
\hline Root length/cm & $68.14 \pm 0.81 \mathrm{~B}$ & $85.25 \pm 0.57 \mathrm{~A}$ & $70.48 \pm 1.88 \mathrm{~B}$ \\
\hline Surface area $/ \mathrm{cm}^{2}$ & $11.59 \pm 0.10 \mathrm{C}$ & $22.97 \pm 0.72 \mathrm{~A}$ & $13.70 \pm 0.31 \mathrm{~B}$ \\
\hline Average diameter/mm & $0.53 \pm 0.00 \mathrm{C}$ & $0.56 \pm 0.01 \mathrm{~A}$ & $0.55 \pm 0.00 \mathrm{~B}$ \\
\hline Apical number & $100.90 \pm 2.13 C$ & $147.20 \pm 0.99 \mathrm{~A}$ & $123.20 \pm 2.09 \mathrm{~B}$ \\
\hline Bifurcation number & $17.20 \pm 0.36 \mathrm{C}$ & $30.00 \pm 0.63 \mathrm{~A}$ & $22.60 \pm 0.83 \mathrm{~B}$ \\
\hline
\end{tabular}
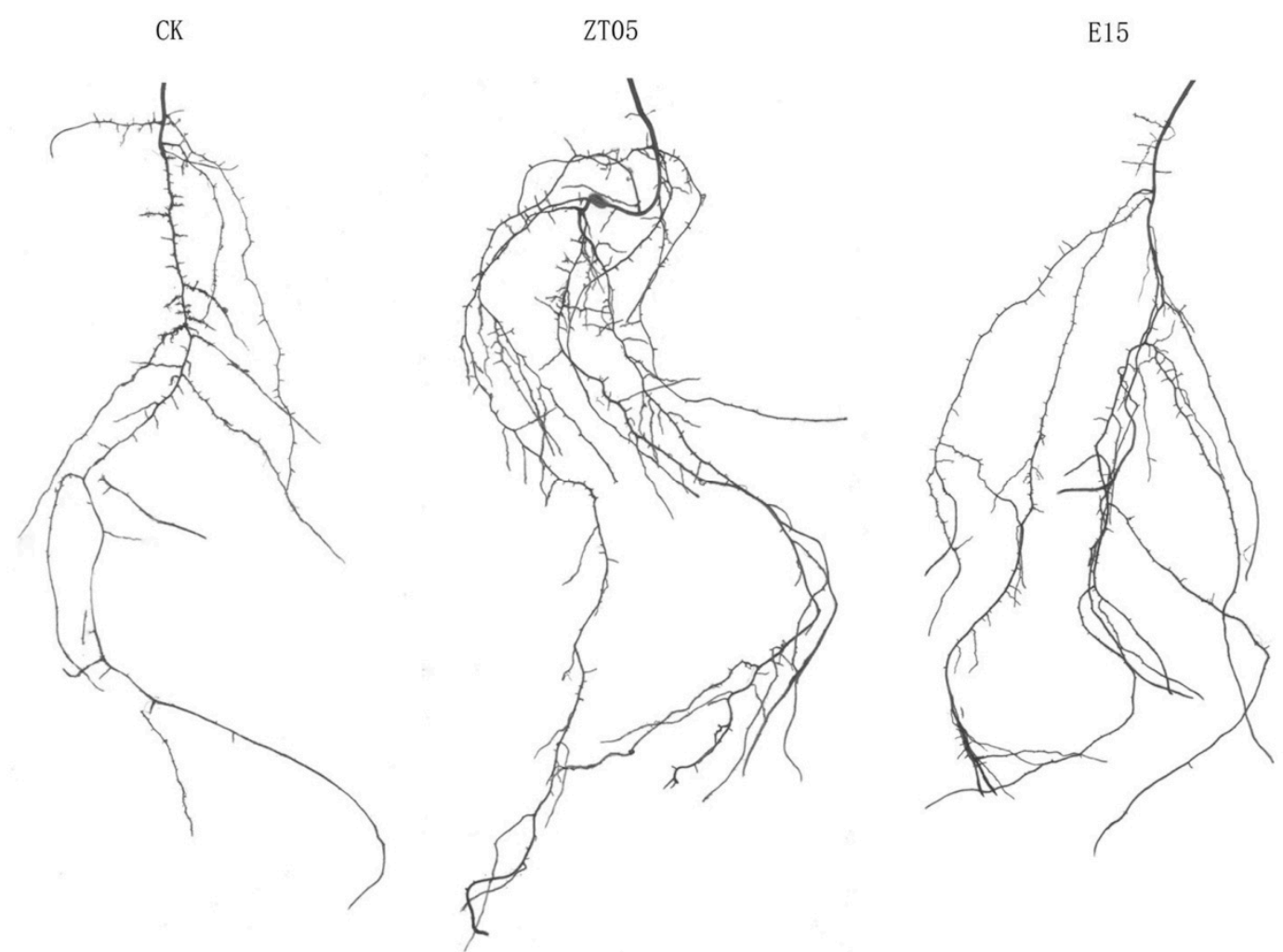

Figure 2. Effects of Trichoderma inoculation on seedling root structure of CK, ZT05, E15. CK: inoculation with PD blank culture medium. ZT05: single inoculation with T. virens ZT05. E15: single inoculation with T. harzianum E15. 


\subsection{Effects of Trichoderma Inoculation on Physicochemical Properties of Seedling Rhizosphere Soil}

As shown in Table 2, significant differences were observed between the control and ZT05 and E15 treatment groups $(p<0.05)$. Specifically, the organic content of the control group was higher than that of the treatment groups inoculated with Trichoderma. This may have been due to the high capacity of Trichoderma to transform soil nutrients. Specifically, Trichoderma species can rapidly degrade nutrients produced by photosynthesis into a state in which they can be used for plant growth. The ability of T. virens ZT05 to transform soil nutrients was higher than that of T. harzianum E15. Trichoderma inoculation also significantly increased $\mathrm{N}$ and $\mathrm{P}$ nutrient contents in soil. This may be related to the ability of Trichoderma to degrade soil macromolecular nutrients into an effective state for plant utilization, thereby accelerating soil nutrient cycling and energy flow. However, organic matter refers to compounds of different compositions with primary components of $\mathrm{C}, \mathrm{N}$, and $\mathrm{P}$. Total potassium levels showed no differences in CK, ZT05, and E15 groups $(p<0.05)$, while the levels of available potassium were organized in the order of CK $>$ ZT05 $>$ E15. These differences may have been a result of diversified microbial communities, slower plant growth, and smaller root systems in the control group than the two treatment groups. $\mathrm{CO}_{2}$ released by root respiration as well as protons and organic acids secreted during the growth of root tip cells can lead to a change in $\mathrm{pH}$. In the present study, the soil $\mathrm{pH}$ differed between the treated samples and the CK group $(p<0.05)$, with the $\mathrm{pH}$ values of samples treated with ZT05 and E15 increasing by $1.23 \%$ and $1.06 \%$, respectively. This may be related to Trichoderma promoting plant growth by reducing plant respiration.

Table 2. Effects of Trichoderma inoculation on soil nutrients and soil enzyme activities of CK, ZT05, E15. CK: inoculation with PD blank culture medium. ZT05: single inoculation with T. virens ZT05. E15: single inoculation with T. harzianum E15. Different letters in the columns indicate significant differences $(p<0.05)$, according to Duncan's new multiple range test.

\begin{tabular}{cccc}
\hline Index & CK & ZT05 & E15 \\
\hline $\mathrm{OM} \mathrm{g} / \mathrm{kg}$ & $84.27 \pm 0.35 \mathrm{~A}$ & $69.77 \pm 0.46 \mathrm{C}$ & $77.91 \pm 0.67 \mathrm{~B}$ \\
$\mathrm{TN} \mathrm{g} / \mathrm{kg}$ & $2.20 \pm 0.01 \mathrm{C}$ & $2.61 \pm 0.00 \mathrm{~A}$ & $2.40 \pm 0.01 \mathrm{~B}$ \\
$\mathrm{AN} \mathrm{mg} / \mathrm{kg}$ & $206.26 \pm 0.03 \mathrm{~B}$ & $219.59 \pm 0.59 \mathrm{~A}$ & $191.41 \pm 0.36 \mathrm{C}$ \\
$\mathrm{TP} \mathrm{g} / \mathrm{kg}$ & $1.87 \pm 0.00 \mathrm{~B}$ & $1.77 \pm 0.00 \mathrm{C}$ & $1.95 \pm 0.00 \mathrm{~A}$ \\
$\mathrm{AP} \mathrm{mg} / \mathrm{kg}$ & $772.14 \pm 0.54 \mathrm{~B}$ & $796.76 \pm 0.54 \mathrm{~A}$ & $459.50 \pm 2.0 \mathrm{C}$ \\
$\mathrm{TK} \mathrm{g} / \mathrm{kg}$ & $7.08 \pm 0.07 \mathrm{~A}$ & $7.13 \pm 0.09 \mathrm{~A}$ & $7.06 \pm 0.12 \mathrm{~A}$ \\
$\mathrm{AK} \mathrm{mg} / \mathrm{kg}$ & $235.86 \pm 0.26 \mathrm{~A}$ & $161.41 \pm 0.48 \mathrm{~B}$ & $135.38 \pm 0.07 \mathrm{C}$ \\
$\mathrm{pH}$ value & $5.68 \pm 0.00 \mathrm{~B}$ & $5.75 \pm 0.01 \mathrm{~A}$ & $5.74 \pm 0.01 \mathrm{~A}$ \\
Sucrase activity U/g & $4.27 \pm 0.01 \mathrm{C}$ & $20.82 \pm 0.01 \mathrm{~A}$ & $14.45 \pm 0.04 \mathrm{~B}$ \\
Catalase activity U/g & $5.15 \pm 0.03 \mathrm{C}$ & $5.97 \pm 0.00 \mathrm{~A}$ & $5.57 \pm 0.05 \mathrm{~B}$ \\
Acid phosphatase & $3.81 \pm 0.09 \mathrm{C}$ & $8.78 \pm 0.02 \mathrm{~A}$ & $5.06 \pm 0.02 \mathrm{~B}$ \\
activity U/g & $938.26 \pm 0.08 \mathrm{C}$ & $1295.74 \pm 0.06 \mathrm{~A}$ & $1094.43 \pm 2.42 \mathrm{~B}$ \\
Urease activity U/g & & & \\
\hline
\end{tabular}

\subsection{Effects of Trichoderma Inoculation on Rhizosphere Soil Enzyme Activity}

Soil enzymes, which comprise the most active organic component in the soil biochemical process, are mainly derived from the secretions of soil microorganisms, plants, and animals. This component plays an important role in soil organic matter circulation and energy conversion. As shown in Table 2, Trichoderma inoculation led to a significant increase in the soil enzyme activity of the rhizosphere soil of seedlings. When compared with the control group, the sucrase, catalase, acid phosphatase, and urease activities of samples treated with ZT05 increased by $387.59 \%, 15.92 \%, 130.45 \%$, and $38.02 \%$, respectively. Sucrase activity, catalase activity, acid phosphatase activity, and urease activity of samples treated with E15 were increased by $238.41 \%, 8.16 \%, 32.81 \%$, and $16.64 \%$, respectively.

Sucrase activity, catalase activity, acid phosphatase activity, and urease activity in samples treated with ZT05 showed increases that were $44.08 \%, 7.18 \%, 42.36 \%$, and $15.54 \%$ greater, respectively, than those seen in samples treated with E15. These results indicate that Trichoderma inoculation played an 
important role in the circulation of nutrients and energy flow in soil, and strain ZT05 specifically had a significant effect on promoting soil enzyme and nutrient cycle activity.

\subsection{Effect on the Diversity of Rhizosphere Fungi of Seedlings}

\subsubsection{Soil Sample Sequencing Results and Sampling Depth Verification}

A total of 541,936 fungal sequences was obtained from nine mixed soil samples in three treatments using the Illumina MiSeqquome PE300 platform. Overall, 358 fungal OTUs were obtained upon OTU clustering at $97 \%$ similarity after separation and elimination. The unique fungal OTUs of CK, ZT05, and E15 groups amounted to 197, 17, and three, respectively. Overall, CK, ZT05, and E15 groups shared 53 OTUs, CK and ZT05 groups shared 62 fungal OTUs, and CK and E15 groups shared 13 fungal OTUs. These findings indicate that the fungal communities of the CK and ZT05 groups were more similar than the pairings of other groups (Figure 3).

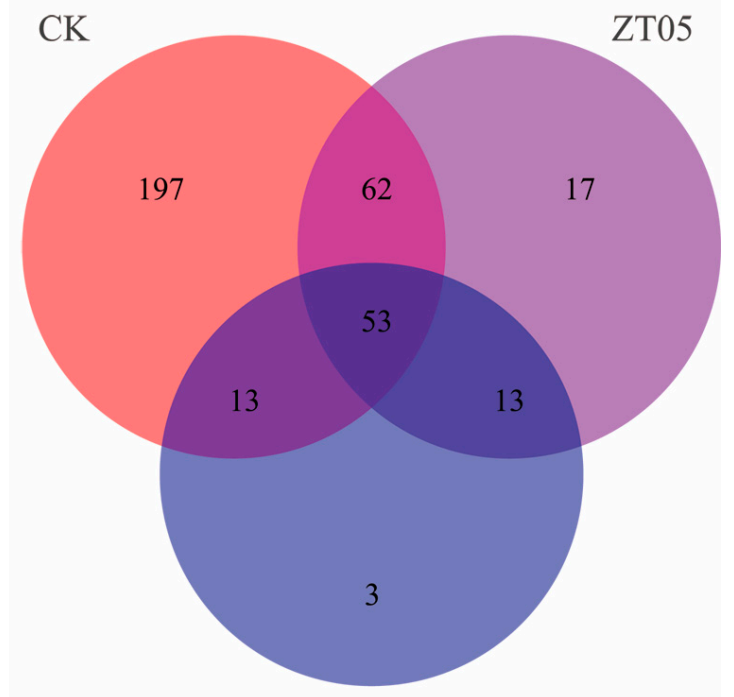

$\mathrm{E} 15$

Figure 3. Venn diagram showing the shared operational taxonomic units (OTUs) of CK, ZT05, E15 treatments. CK: inoculation with PD blank culture medium. ZT05: single inoculation with T. virens ZT05. E15: single inoculation with T. harzianum E15.

\subsubsection{Distribution of Soil Fungal Community}

Categorical analysis of OTU representative sequences using a cutoff of $97 \%$ similarity revealed a total of seven phyla, 19 classes, 56 orders, 89 families, 11 genera, and 197 species of soil fungi. As shown in Figure 4, Ascomycota was the dominant fungi shared by the control, ZT05, and E15 groups (relative abundance $\geq 10 \%$ ). In addition, Ascomycota was dominant in the control group (relative abundance 83.7\%), while the relative abundances of Basidiomycota, Zygomycota, unclassified-k-fungi, and Chytridiomycota were $7.2 \%, 4.57 \%, 4.3 \%$, and $0.086 \%$, respectively. In the ZT05 treatment, Ascomycota was the dominant fungi (relative abundance $84.8 \%$ ), while the relative abundances of Zygomycota, Chytridiomycota, unclassified-k-fungi, and Basidiomycota were $7.17 \%, 6.4 \%, 1.6 \%$, and $0.04 \%$, respectively. For the ZT05 treatment, Ascomycota was the dominant fungi (relative abundance 99.05\%), while the relative abundances of Chytridiomycota, Zygomycota, unclassified-k-fungi, and Basidiomycota were $0.33 \%, 0.31 \%, 0.27 \%$, and $0.03 \%$, respectively. Significant differences were observed in the relevance abundances of Basidiomycota and unclassified-k-Fungi between the control and ZT05 and E15 treatments. The relevance abundance of Zygomycotain in the ZT05 group was significantly different from those of the control and E15 groups. 


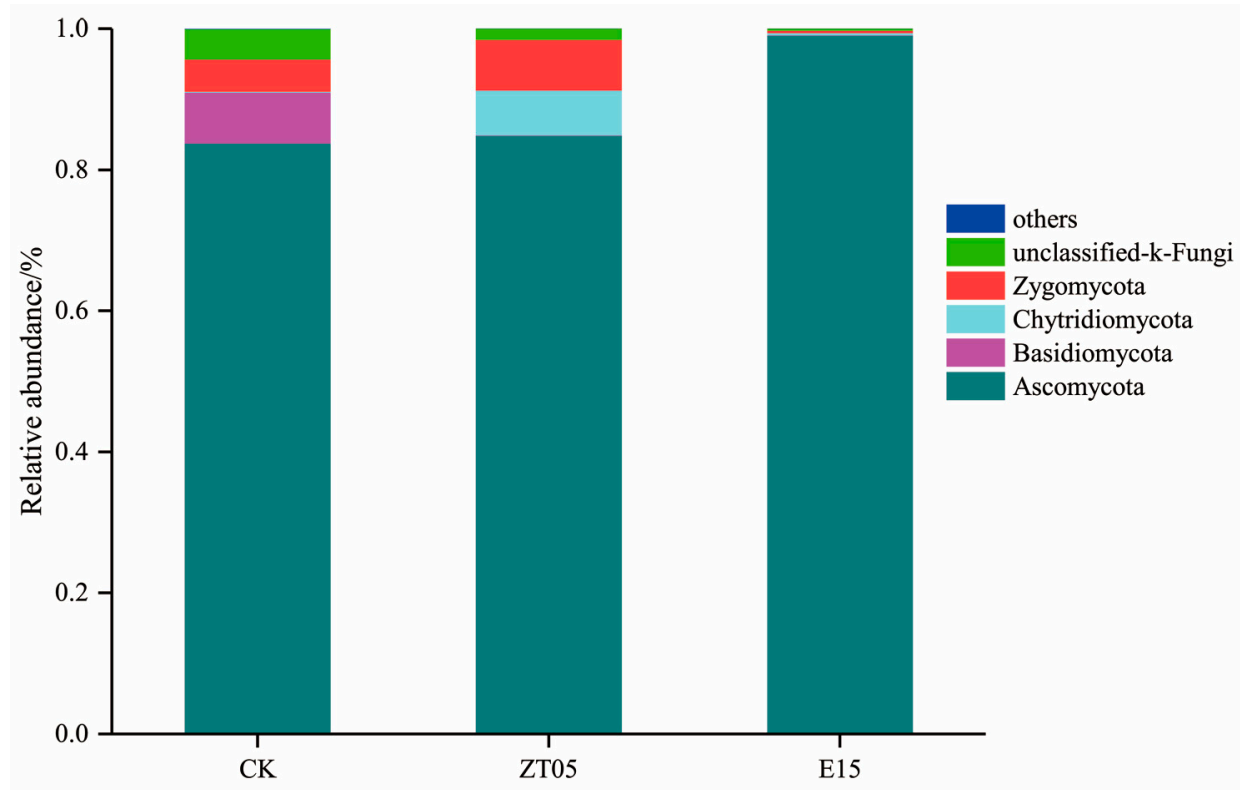

Figure 4. Relative abundance (\%) of fungal phyla among CK, ZT05, E15 treatments, based on total sequence reads. CK: inoculation with PD blank culture medium. ZT05: single inoculation with T. virens ZT05. E15: single inoculation with T. harzianum E15.

The control group contained 134 genera of soil fungi, while the ZT05 group had 65 genera and the E15 group had 33 genera. Figure 5 shows the community analysis of the top 10 fungi at the genus level. In the control group, Fusarium, Phoma, and Gibberella were the dominant fungi genera (relative abundance\%), while the relative abundances of Trichoderma, Penicillium, Mortierella, Sphaerosporella, Rhizophlyctis, unclassified-k-fungi, and Monographella were 1.09\%, 5.16\%, 1.72\%, 7.31\%, $0.08 \%, 4.34 \%$, and $3.99 \%$, respectively. For the ZT05 group, Trichoderma was the dominant fungi (relative abundance $76.40 \%$ ), while the relative abundances of Fusarium, Phoma, Gibberella, Penicillium, Mortierella, Sphaerosporella, Rhizophlyctis, unclassified-k-fungi, and Monographella were $0.14 \%, 0.001 \%$, $0.06 \%, 6.6 \%, 7.2 \%, 0.00 \%, 6.36 \%, 1.5 \%$, and $0.0006 \%$, respectively. For the E15 group, Trichoderma was the dominant fungi (relative abundance $98.41 \%$ ), while the abundances of all the other genera were less than $0.33 \%$. 


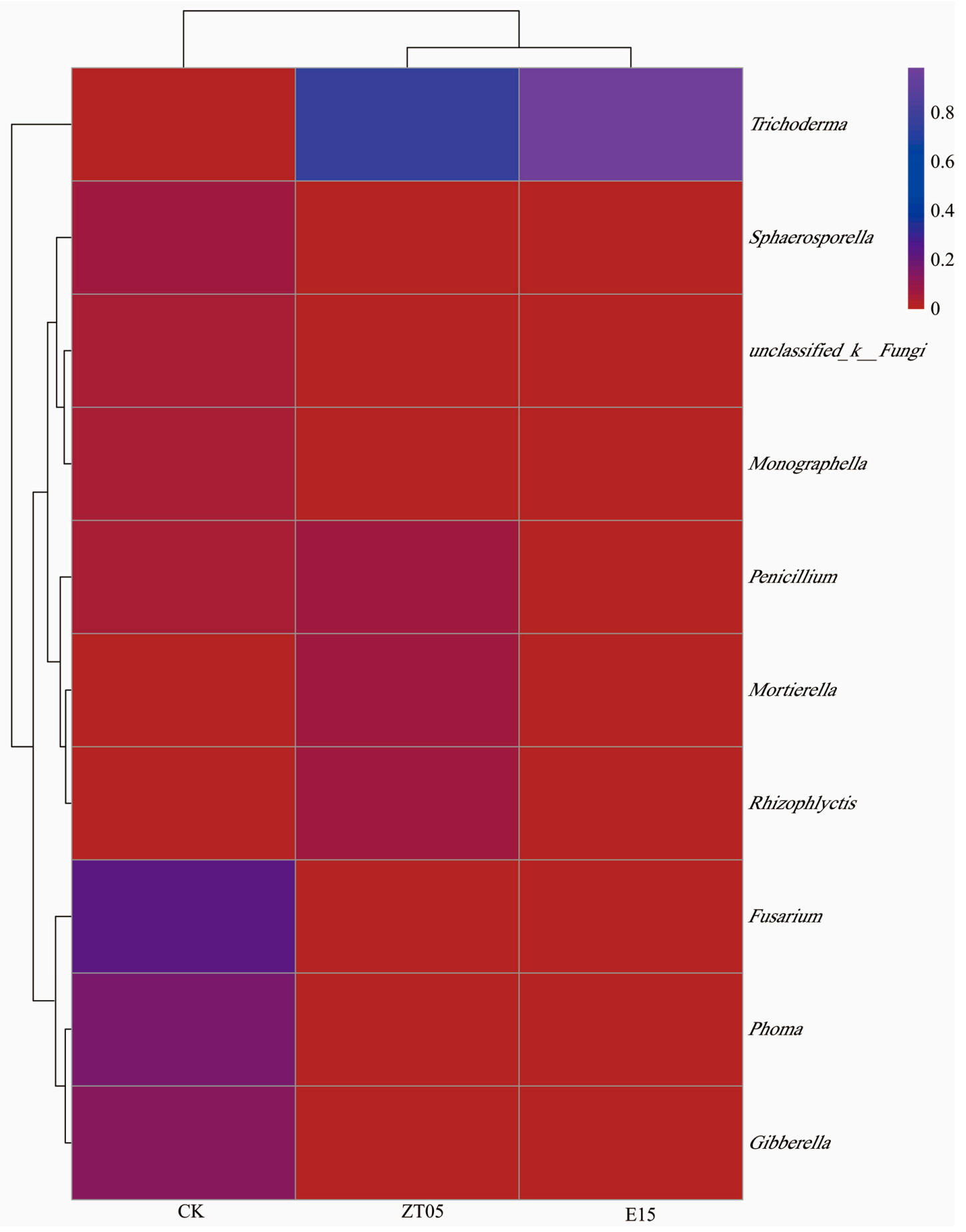

Figure 5. Heat map showed the relative abundance of the top 10 genes at CK, ZT05, E15 treatments. CK: inoculation with PD blank culture medium. ZT05: single inoculation with T. virens ZT05. E15: single inoculation with T. harzianum E15.

\subsubsection{Analysis of $\alpha$ Diversity Index}

ANOVA of the ITS rDNA diversity index of the CK, ZT05, and E15 soil samples was conducted. As shown in Table 3, the coverage indexes of the CK, ZT05, and E15 groups were close to 1, and they did not differ significantly. These findings indicate that the sequencing results could accurately reflect the actual situation of the tested soil samples. The Ace and Chao1 indexes of the soil samples were found to be in the order of CK $>$ ZT05 $>$ E15, with obvious differences observed between CK and the two treatment groups $(p<0.05)$. No significant difference was observed between the ZT05 and E15 
groups, indicating that the total number and the richness of fungi in CK soil were higher than those in the two treatment groups. The total number and the richness of fungi communities in the ZT05 group were greater than those in the E15 group, but this difference was not significant. The Shannon index was found to be in the order of CK > ZT05 > E15, with significant differences observed between $\mathrm{CK}$ and the two treatment groups. No great difference was observed between the two treatments, indicating that the fungal richness of CK soil was higher than those of the other two groups. The Simpson index was found to be in the order of CK > E15 > ZT05, with significant differences observed between CK and the two treatment groups, but not between ZT05 and E15. These findings indicate that the complexity of CK soil was greater than that of the soil in ZT05 and E15 treatment groups; furthermore, the complexity of ZT05 soil was greater than that of E15 soil, but not significantly.

Table 3. Effects of Trichoderma inoculation on diversity indices of the soil fungal community in the CK, ZT05, E15. CK: inoculation with PD blank culture medium; ZT05: single inoculation with T. virens ZT05; E15: single inoculation with T. harzianum E15. Different letters in the columns indicate significant differences $(p<0.05)$, according to Duncan's new multiple range test.

\begin{tabular}{cccccc}
\hline Samples & $\begin{array}{c}\text { Shannon } \\
\text { Index }\end{array}$ & Simpson Index & Chao1 Index & ACE Index & Coverage \% \\
\hline CK & $2.85 \pm 0.44 \mathrm{~A}$ & $0.151 \pm 0.07 \mathrm{~A}$ & $260.04 \pm 16.39 \mathrm{~A}$ & $257.51 \pm 17.23 \mathrm{~A}$ & $0.99 \pm 0.00 \mathrm{~A}$ \\
ZT05 & $1.21 \pm 0.15 \mathrm{~B}$ & $0.54 \pm 0.08 \mathrm{~B}$ & $116.24 \pm 3.43 \mathrm{~B}$ & $119.25 \pm 3.71 \mathrm{~B}$ & $0.99 \pm 0.00 \mathrm{~A}$ \\
E15 & $0.58 \pm 0.02 \mathrm{~B}$ & $0.71 \pm 0.01 \mathrm{~B}$ & $82.72 \pm 5.71 \mathrm{~B}$ & $100.71 \pm 12.45 \mathrm{~B}$ & $0.99 \pm 0.00 \mathrm{~A}$ \\
$p$ & 0.002 & 0.001 & 0.00 & 0.00 & 0.03 \\
\hline
\end{tabular}

Pearson's analysis was used to analyze the correlation between the $\alpha$ diversity index and the physicochemical properties and enzyme activity (Table 4). The Ace, Chao1, and Shannon indexes were positively correlated with organic matter, available nitrogen, available phosphorus, and available potassium contents. In addition, theChao1 index was significantly positively correlated with the available potassium $\left(R^{2}=1.00^{* *}, p<0.05,{ }^{* *}\right.$ indicates a very significant difference), while the Ace, Chao1, and Shannon indexes were negatively correlated with $\mathrm{pH}$, total nitrogen, total phosphorus, sucrase activity, catalase activity, urease activity, and acid phosphatase activity. These findings indicate that Trichoderma has a crucial effect on soil nutrient cycling.

Table 4. Correlation analysis of diversity indices and soil properties. The correlation coefficient and significance were obtained using Pearson correlation analysis. Significant values are shown as: ** $p<0.01$.

\begin{tabular}{ccccccccccccc}
\hline & $\begin{array}{c}\text { pH } \\
\text { Value }\end{array}$ & $\begin{array}{c}\text { Organic } \\
\text { Matter }\end{array}$ & $\begin{array}{c}\text { Available } \\
\text { Nitrogen }\end{array}$ & $\begin{array}{c}\text { Total } \\
\text { Nitrogen }\end{array}$ & $\begin{array}{c}\text { Available } \\
\text { Phosphorus }\end{array}$ & $\begin{array}{c}\text { Total } \\
\text { Phosphorus }\end{array}$ & $\begin{array}{c}\text { Available } \\
\text { Potassium }\end{array}$ & $\begin{array}{c}\text { Total } \\
\text { Potassium }\end{array}$ & $\begin{array}{c}\text { Sucrase } \\
\text { Activity }\end{array}$ & $\begin{array}{c}\text { Catalase } \\
\text { Activity }\end{array}$ & $\begin{array}{c}\text { Urease } \\
\text { Activity }\end{array}$ & $\begin{array}{c}\text { Acid } \\
\text { Phosphatase } \\
\text { Activity }\end{array}$ \\
\hline Ace & -0.97 & 0.76 & 0.29 & -0.80 & 0.55 & -0.04 & 1.00 & -0.13 & -0.88 & -0.82 & -0.76 & -0.61 \\
Chao1 & -0.95 & 0.72 & 0.36 & -0.75 & 0.60 & -0.12 & 1.00 & -0.64 & -0.84 & -0.77 & -0.71 & -0.56 \\
Shannon & -0.92 & 0.65 & 0.49 & -0.69 & 0.68 & -0.21 & 1.00 & 0.03 & -0.79 & -0.71 & -0.64 & -0.47 \\
Simpson & 0.90 & -0.62 & -0.48 & 0.66 & -0.71 & 0.25 & -0.99 & -0.07 & 0.76 & 0.68 & 0.61 & 0.44 \\
\hline
\end{tabular}

\subsubsection{Analysis of $\beta$ Diversity Index}

The Bray-Curtis matrix was used to measure the heterogeneity of different sample communities in the soils. As shown in Figure 6, CK, ZT05, and E15 groups were distributed in different quadrants and the distribution distance was large, indicating that the composition of CK, ZT05, and E15 samples differed greatly. Nonparametric results were subjected to ANOSIM, which revealed that the differences between the fungal groups in the CK, ZT05, and E15 soil samples were greater than the within-group differences $(R=1)$, and that the differences were significant $(p=0.003)$. 


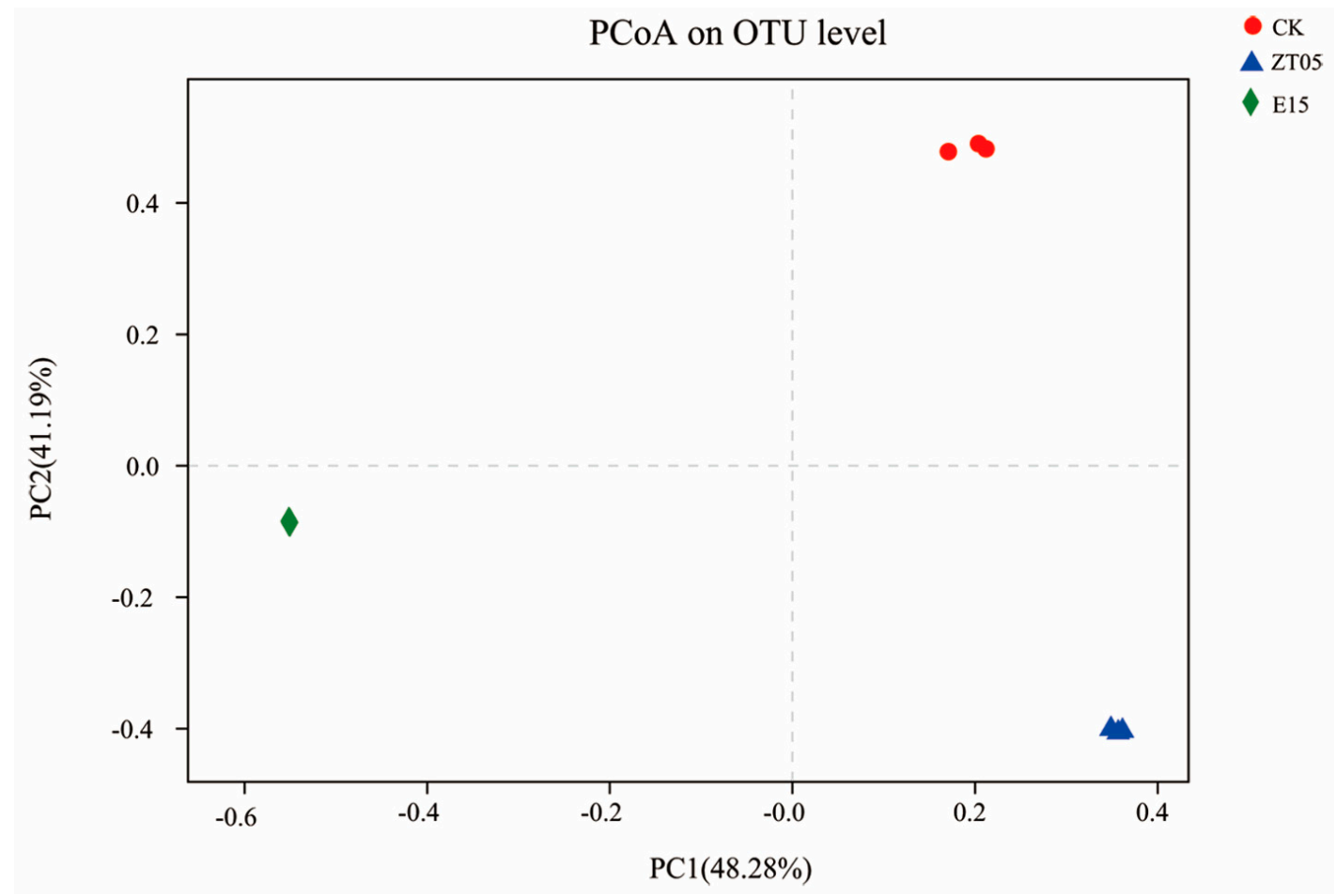

Figure 6. PCoA(Principal co-ordinates analysis) ordination based on Bray-Curtis similarities of fungal communities at CK, ZT05, E15 treatments. CK: inoculation with PD blank culture medium. ZT05: single inoculation with T. virens ZT05. E15: single inoculation with T. harzianum E15.

\section{Discussion}

Trichoderma spp. are soil fungi widely distributed in the natural environment which form symbioses with many plants [47]. The interaction between the plant rhizosphere and soil microorganisms plays an important role in plant growth, yield, nutrient cycling, and energy conversion in soil [48]. Plant root exudates promote the colonization of rhizosphere microorganisms, while soil microorganisms improve plant growth and increase the amount of nutrients in the soil environment by effectively utilizing plant photosynthates [49]. The beneficial effects of Trichoderma spp. can be divided into direct and indirect beneficial effects. The direct beneficial effects include promoting plant growth, promoting and improving plant root growth and structure [50], improving seed vigor and growth [51,52], and decomposing, recycling, and utilizing soil nutrients $[4,53,54]$. Our results show that inoculation with T. harzianum E15 and T. virens ZT05 could significantly promote seedling growth and change root structure in annual seedlings of $P$. sylvestris var. mongolica. The growth of seedlings inoculated with E15 was significantly higher than that of seedlings inoculated with ZT05, and the growth and structure of seedling roots inoculated with ZT05 was higher than that of seedling roots inoculated with E15.Many reports have shown that Trichoderma inoculation has significant promotion effects on plants seedlings and crops yields, such as those of cotton [54], tomato [55], and Leymus chinensis [8,30]. Harman [7] showed that the inoculation of Trichoderma spp. in maize could significantly promote plant growth, change root structure, and increase root activity. Shen [56], Fu [57], and Xiong [58] demonstrated that a Trichoderma agent stimulated banana root growth, promoted plant growth, and increased fruit yield. Hung [59] and Zhang [30] showed that a mixture of organic fertilizer and a Trichoderma agent could significantly improve plant growth and crop yield. Trichoderma could be used as an organic fertilizer as a growth substrate to degrade soil nutrients and improve the ability of plant photosynthesis, thereby improving plant growth. IAA is a molecule that is synthesized by plants and a few microbes [60]. In plants, IAA plays a key role in root and shoot development. The hormone moves from one part of the plant to another by specific transporter systems that involve auxin importer (AUX1) and efflux (PIN1-7) proteins. IAA is a key regulator of lateral root development 
and root hair development [61]. Studies have shown that all Trichoderma spp. isolated from different geographical areas can secrete IAA and promote the growth of cucumber, bottle gourd, and bitter gourd [61]. Contreras-Cornejo [5] showed that IAA, a mycelial secretion of Trichoderma spp., could significantly improve plant and lateral root growth. The volatile and non-volatile secondary metabolites of Trichoderma spp.-including 6-n-pentyl-6H-pyran-2-one (6PP), gliotoxin, viridin, harzianopyridone, harziandione, and peptaibols $[62,63]$ - have a significant growth-promoting effect on plants $[7,64]$. Vinale [65] showed that secondary metabolites of T. harzianum commercial strains T22 and T39, T. atroviride P1, and T. harzianum A6 also had significant growth-promoting effects on plant growth.

In this study, Trichoderma inoculation was found to significantly increase the nutrient content and soil enzyme activity in rhizosphere soil of P. sylvestris var. mongolica seedlings. T. virens ZT05 had a more significant effect on soil nutrient and enzyme activity in the rhizosphere of seedlings compared to T. harzianum E15. Many nutrient elements in soil exist in a slightly soluble or insoluble state, which limits the normal circulation of nutrients in soil. Trichoderma spp. can change the $\mathrm{pH}$ value of plants in the rhizosphere soil and secrete organic acids to degrade minerals such as large amounts of elements $(\mathrm{P})$ and trace elements ( $\mathrm{Fe}, \mathrm{Mn}$, and $\mathrm{Zn}$ ), and activate soil nutrients, thus promoting the uptake of nutrients by plants as well as the recycling and utilization of nutrients in the soil environment $[50,66,67]$. At the same time, Trichoderma spp. have a strong colonization ability which, with the growth and extension of the root system, can increase the contact area between root and soil and increase the secretion of extracellular enzymes such as sucrase, urease, phosphatase, and organic acids in the rhizosphere, so as to improve the nutrient cycle and enzyme activity in the soil $[6,68,69]$. Yedidia [70] showed that under a hydroponic system, T. harzianum T203 could significantly increase the nutrient conversion and absorption of $\mathrm{P}, \mathrm{Fe}, \mathrm{Mn}, \mathrm{Zn}, \mathrm{Cu}$, and $\mathrm{Na}$, thus promoting cucumber growth and yield. Khan [19] showed that Trichoderma spp. can significantly improve the degradation and absorption of $\mathrm{P}, \mathrm{K}, \mathrm{Ca}, \mathrm{Mg}$, $\mathrm{Cu}, \mathrm{Fe}, \mathrm{Mn}$, and $\mathrm{Zn}$ in fertilizers. Li [71] showed that the inoculation of tomato plants with Trichoderma asperellum CHF78 could significantly increase the soil's available nutrient content and plant nutrient uptake ability. Zhai showed that T. asperellum ACCC30536 improved the yield of A. annua, while the moisture, $\mathrm{pH}$ stability, organic matter content, and availability of nitrogen, phosphorus, and potassium in inoculated soil were also significantly improved [72]. El-Katatny found that Trichoderma spp. are important soil microorganisms that can have a significant effect on soil phosphorus, potassium, and nitrogen fixation, as well as on the restoration of degraded soil environments [67].

In this study, the Illumina Miseqquome PE300 high-throughput sequencing results show that Ascomycota was the dominant group in the rhizosphere soil of all treatments-CK, ZT05, and E15-and the relative abundance of Ascomycota in the E15 treatment rhizosphere soil was $99.05 \%$. At the genus level, Fusarium, Phoma, and Gibberella were dominant in the CK treatment, while Trichoderma was the dominant genus in the ZT05 and E15 treatments. The results of the alpha and beta diversity analyses showed that Trichoderma spp. inoculation had a significant effect on the community structure of fungi in the rhizosphere soil of seedlings; this is consistent with the research results of Yu [73], Shen [60], Zhang [30]. Trichoderma spp. have the advantages of fast growth and vigorous vitality; thus, they can occupy the growing space quickly and absorb the required nutrients. At the same time, Trichoderma spp. can secrete cell wall-degrading enzymes including chitinases, cellulases, xylanases, glucanases, and proteinases, which can degrade microbial cells in the soil environment to absorb nutrients, thus changing the structure of the microbial community [22,23]. Stefania [74] showed that lemon plant soil microbial biomass increased by $46 \%$ after Trichoderma inoculation. Likewise, Mclean [75] showed that Trichoderma inoculation could change soil nutrient content and the soil microbial community structure of grassland soil.

\section{Conclusions}

1. Trichoderma inoculation increased the total biomass, seedling height, ground diameter, root length, root area, root diameter, number of root tips, and number of branches of $P$. sylvestris var. mongolica seedlings, thereby increasing the absorption area and growth potential of seedlings. The 
contribution of T. harzianum E15 to seedling height, ground diameter, and total biomass was more significant. ZT05 had greater effects on root length, root area, root diameter, number of root tips, and bifurcation of seedlings.

2. Trichoderma inoculation increased soil nutrient content and soil enzyme activity in the rhizosphere soil of $P$. sylvestris var. mongolica annual seedlings. Specifically, Trichoderma inoculation had a significant effect on the community structure of fungi in the rhizosphere soil of seedlings, especially at the genus level.

Author Contributions: S.H., X.D., and R.S. conceived and designed the study. S.H., X.D., and Y.A. performed the experiments. S.H., X.D. and X.S. contributed to the sample measurement and data analysis. S.H. and X.D. wrote the paper.

Funding: This research was funded by [National Key Research and Development Program] grant number (2017YFD0600101), [National Natural Science Foundation of China] grant number $(31670649,31700564,31170597$, 31200484).

Conflicts of Interest: The authors declare no conflict of interest.

\section{References}

1. Lorito, M.; Harman, G.E.; Mastouri, F. Translational research on Trichoderma: From omics to the field. Annu. Rev. Phytopathol. 2010, 48, 395-417. [CrossRef] [PubMed]

2. Brotman, Y.; Kapuganti, J.G.; Viterbo, A. Trichoderma. Curr. Biol. 2010, 20, R390-R391. [CrossRef] [PubMed]

3. Yedidia, I.I.; Benhamou, N.; Chet, I.I. Induction of Defense Responses in Cucumber Plants (Cucumis sativus L.) by the Biocontrol Agent Trichoderma harzianum. Appl. Environ. Microbiol. 1999, 65, 1061-1070. [PubMed]

4. Shoresh, M.; Harman, G.E.; Mastouri, F. Induced Systemic Resistance and Plant Responses to Fungal Biocontrol Agents. Annu. Rev. Phytopathol. 2010, 48, 21-43. [CrossRef] [PubMed]

5. Contreras-Cornejo, H.A.; Macias-Rodriguez, L.; Cortes-Penagos, C.; Lopez-Bucio, J. Trichoderma virens, a plant beneficial fungus, enhances biomass production and promotes lateral root growth through an auxin-dependent mechanism in Arabidopsis. Plant Physiol. 2009, 149, 1579-1592. [CrossRef] [PubMed]

6. López-Bucio, J.; Pelagio-Flores, R.; Herrera-Estrella, A. Trichoderma as biostimulant: Exploiting the multilevel properties of a plant beneficial fungus. Sci. Hortic. 2015, 196, 109-123. [CrossRef]

7. Harman, G.E.; Howell, C.R.; Viterbo, A.; Chet, I.; Lorito, M. Trichoderma species-Opportunistic, avirulent plant symbionts. Nat. Rev. Microbiol. 2004, 2, 43-56. [CrossRef] [PubMed]

8. Zhang, F.; Yuan, J.; Yang, X.; Cui, Y.; Chen, L.; Ran, W.; Shen, Q. Putative Trichoderma harzianum mutant promotes cucumber growth by enhanced production of indole acetic acid and plant colonization. Plant Soil 2013, 368, 433-444. [CrossRef]

9. Anil, K.; Lakshmi, T. Phosphate solubilization potential and phosphatase activity of rhizospheric Trichoderma spp. Braz. J. Microbiol. 2010, 41, 787-795.

10. Saravanakumar, K.; Shanmuga, A.V.; Kathiresan, K. Effect of Trichoderma on soil phosphate solubilization and growth improvement of Avicennia marina. Aquat. Bot. 2013, 104, 101-105. [CrossRef]

11. Elena, B.; Paolo, A.; Fabio, P.; Moreno, T. Use of Trichoderma Spp. and Arbuscular Mycorrhizal Fungi to Increase Soil Beneficial Population of Bacteria in a Nectarine Commercial Orchard: Effect on Root Growth, Nutrient Acquisition and Replanting Disease. J. Plant Nutr. 2015, 39, 1147-1155.

12. Zhang, F.; Zhu, Z.; Yang, X.; Ran, W.; Shen, Q. Trichoderma harzianum T-E5 significantly affects cucumber root exudates and fungal community in the cucumber rhizosphere. Appl. Soil Ecol. 2013, 72, 41-48. [CrossRef]

13. Savazzini, F.; Longa, C.M.O.; Pertot, I. Impact of the biocontrol agent Trichoderma atroviride SC1 on soil microbial communities of a vineyard in northern Italy. Soil Biol. Biochem. 2009, 41, 1457-1465. [CrossRef]

14. Zhou, X.; Jia, H.; Ge, X.; Wu, F. Effects of vanillin on the community structures and abundances of Fusarium and Trichoderma spp. in cucumber seedling rhizosphere. J. Plant Interact. 2018, 13, 45-50. [CrossRef]

15. Chang, Y.C.; Chang, Y.C.; Baker, R.; Kleifeld, O.; Chet, I. Increased growth of plants in the presence of the biological control agent Trichoderma harzianum. Plant Dis. 1986, 70, 145-148. [CrossRef]

16. Eugenia, M.D.; Belén; Sara, D.; Hermosa, R.; Monte, E.; Carlos, N. Transcriptomic response of Arabidopsis thaliana after $24 \mathrm{~h}$ incubation with the biocontrol fungus Trichoderma harzianum. J. Plant Physiol. 2012, 169, 614-620. 
17. Contreras-Cornejo, H.; Macías-Rodríguez, L.I.; Alfaro, C.R.; López-Bucio, J. Trichoderma spp. Improve growth of Arabidopsis seedlings under salt stress through enhanced root development, osmolite production, and $\mathrm{Na}^{+}$ elimination through root exudates. Mol. Plant Microbe Interact. 2014, 27, 503-514. [CrossRef] [PubMed]

18. Maeda, K.; Spor, A.; Edel-Hermann, V.; Heraud, C.; Breuil, M.C.; Bizouard, F.; Toyoda, S.; Yoshida, N.; Steinberg, C.; Philippot, L. $\mathrm{N}_{2} \mathrm{O}$ production, a widespread trait in fungi. Sci. Rep. 2015, 5, 9697. [CrossRef]

19. Khan, M.Y.; Haque, M.M.; Molla, A.H.; Rahman, M.; Alam, M.Z. Antioxidant compounds and minerals in tomatoes by, Trichoderma-enriched biofertilizer and their relationship with the soil environments. J. Integr. Agric. 2017, 16, 691-703. [CrossRef]

20. Harman, G.E. Multifunctional fungal plant symbionts: New tools to enhance plant growth and productivity. New Phytol. 2011, 189, 647-649. [CrossRef]

21. Mbarki, S.; Cerdà, A.; Brestic, M.; Mahendra, R.; Abdelly, C.; Pascual, J.A. Vineyard compost supplemented with $\backslash \mathrm{r}$, trichodermaharzianum $\backslash \mathrm{r}$, t78 improve saline soil quality. Land Degrad. Dev. 2016, 28, 1028-1037. [CrossRef]

22. Zhang, F.G. The Affects and Mechanisms of Puta Five Trichoredma harzianum Mutant and ITS Bio-Organic Fertilizer on Growth of Cucumber; Nanjing Agricultural University: Nanjing, China, 2015; pp. 15-18.

23. Assigbetsé, K.; Ciss, I.; Bakhoum, N.; Dieng, L. Effect of inoculation of acacia senegal mature trees with mycorrhiza and rhizobia on soil properties and microbial community structure. In Proceedings of the EGU General Assembly Conference Abstracts, Vienna, Austria, 22-27 April 2012; pp. 2012-8004.

24. Wagner, K.; Apostolakis, A.; Daliakopoulos, I.; Tsanis, I. Can Tomato Inoculation with Trichoderma Compensate Yield and Soil Health Deficiency due to Soil Salinity? In Proceedings of the Egu General Assembly Conference Abstracts, Vienna, Austria, 17-22 April 2016. [CrossRef]

25. Yadav, R.L.; Shukla, S.K.; Suman, A.; Singh, P.N. Trichoderma inoculation and trash management effects on soil microbial biomass, soil respiration, nutrient uptake and yield of ratoon sugarcane under subtropical conditions. Biol. Fertil. Soils 2009, 45, 461-468. [CrossRef]

26. Zhu, J.-J.; Li, F.-Q.; Xu, M.-L.; Kang, H.-Z.; Wu, X.-Y. Le rôle des champignons ectomycorrhiziens dans la réduction du dépérissement du pin sur sols sableux semi-arides du nord de la Chine: Une approche expérimentale. Ann. For. 2008, 65, 304.

27. Yin, D.C.; Deng, X.; Ilan, C.; Song, R.Q. Physiological Responses of Pinus sylvestris var. Mongolica Seedlings to the Interaction Between Suillus luteus and Trichoderma virens. Curr. Microbiol. 2014, 69, 334-342. [CrossRef] [PubMed]

28. Yin, D.C.; Song, R.Q.; Qi, J.Y.; Deng, X. Ectomycorrhizal fungus enhances drought tolerance of Pinus sylvestris var. mongolica seedlings and improves soil condition. J. For. Res. 2018, 29, 1775-1788. [CrossRef]

29. John, C.J.; Jishma, P.; Karthika, N.R.; Nidheesh, K.S.; Radhakrishnan, E.K. Pseudomonas fluorescens R68 assisted enhancement in growth and fertilizer utilization of Amaranthus tricolor (L.). 3 Biotech 2017, 7, 256. [CrossRef] [PubMed]

30. Zhang, F.G.; Huo, Y.Q.; Cobb, A.B.; Luo, G.W.; Zhou, J.Q.; Yang, G.W.; Gail, W.T.W.; Zhang, Y.J. Trichoderma biofertilizer links to altered soil chemistry, altered microbial communities, and improved grassland biomass. Front. Microbiol. 2018, 9, 848. [CrossRef] [PubMed]

31. Nunzio, F.; Valeria, V.; Woo, S.L.; Olimpia, P.; Armando, D.R.; Laura, G.; Romano, I.; Lombardi, N.; Napolitano, M.; Colla, G.; et al. Trichoderma-Based Biostimulants Modulate Rhizosphere Microbial Populations and Improve N Uptake Efficiency, Yield, and Nutritional Quality of Leafy Vegetables. Front. Plant Sci. 2018, 9, 743.

32. Yin, D.C.; Deng, X.; Chet, I. Inhibiting effect and mechanism of Trichoderma virens T43 on four major species of forest pathogen. Chin. J. Ecol. 2014, 33, 1911-1919.

33. Yin, D.C.; Yang, L.B.; Deng, X.; Chet, I. Song RQ How Trichoderma virens affects growth indicators, physiological and biochemical parameters of Pinus sylvestris var. mongolica seedlings. J. Beijing For. Univ. 2015, 37, 78-83.

34. Qi, J.Y.; Yin, D.C.; Song, R.Q. Effects of Suillusluteus on Salt Resistance of Pinussylvestris var. mongolica Seedlings. J. Jilin Agric. Univ. 2019, 50, 108-113.

35. Deng, X.; Song, X.S.; Song, R.Q. Effect of inoculating Phialocephala fortinii D575 and Suillus luteus N94 on the growth of Pinus sylvestris var. mongolica and its resistant to damping-off. For. Pest Dis. Jan. 2017, 36, 21-25.

36. Bao, S.D. Soil and Plant Analysis, 3rd ed.; Agricultural Press of China: Beijing, China, 2000; pp. 25-109. 
37. Collignon, C.; Uroz, S.; Turpault, M.P.; Frey-Klett, P. Seasons differently impact the structure of mineral weathering bacterial communities in beech and spruce stands. Soil Biol. Biochem. 2011, 43, $2012-2022$. [CrossRef]

38. Shanmugam, V.; Verma, R.; Rajkumar, S.; Naruka, D.S. Bacterial diversity and soil enzyme activity in diseased and disease free apple rhizosphere soils. Ann. Microbiol. 2011, 61, 765-772. [CrossRef]

39. Caporaso, J.G.; Kuczynski, J.; Stombaugh, J.; Bittinger, K.; Bushman, F.D.; Costello, E.K.; Fierer, N.; peña, A.G.; Goodrich, J.K.; Gordon, J.I.; et al. QIIME allows analysis of high-throughput community sequencing data. Nat. Methods 2010, 7, 335-336. [CrossRef] [PubMed]

40. Magoc, T.; Salzberg, S.L. FLASH: Fast length adjustment of short reads to improve genome assemblies. Bioinformatics 2011, 27, 2957-2963. [CrossRef] [PubMed]

41. Edgar, R.C. UPARSE: Highly accurate OTU sequences from microbial amplicon reads. Nat. Methods 2013, 10, 996-998. [CrossRef]

42. Uroz, S.; Oger, P.; Tisserand, E.; Cébron, A.; Turpault, M.P.; Buée, M.; Boer, W.D.; Leveau, J.H.J.; Frey-Klett, P. Specific impacts of beech and Norway spruce on the structure and diversity of the rhizosphere and soil microbial communities. Sci. Rep. 2016, 6, 27756. [CrossRef]

43. Yang, L.B.; Sui, X.; Zhu, D.G.; Cui, F.X.; Li, J.B.; Song, R.Q.; Ni, H.W. Study on fungal communities characteristics of different Larixgmelini forest types in cold temperate zone. J. Cent. South Univ. For. Technol. 2017, 37, 12.

44. Sui, X.; Zhang, R.T.; Yang, L.B.; Xu, N.; Chai, C.R.; Wang, J.F.; Fu, X.L.; Zhong, H.X.; Xing, J.H.; Zhang, Y.; et al. Effect of simulation nitrogen deposition on bacterial diversity of Deyeuxia angustifolia in wetland of Sanjiang plain. Pratacult. Sci. 2016, 33, 589-598.

45. Yong, C.; Jiang, Y.M.; Huang, H.; Muo, L.C.; Ru, J.L.; Zhao, J.H.; Xiao, S. Long-term and high-concentration heavy-metal contamination strongly influences the microbiome and functional genes in Yellow River sediments. Sci. Total Environ. 2018, 637, 1400-1412. [CrossRef]

46. Zhou, J.Z.; Deng, Y.; Shen, L.N.; Wen, C.Q.; Wen, C.Q.; Yan, Q.Y.; Ning, D.L.; Qin, Y.J.; Xue, K.; Wu, L.Y.; et al. Temperature mediates continental-scale diversity of microbes in forest soils. Nat. Commun. 2016, 7, 12083. [CrossRef] [PubMed]

47. Druzhinina, I.S.; Seidl-Seiboth, V.; Herrera-Estrella, A.; Horwitz, B.A.; Kenerley, C.M.; Monte, E.; Kubicek, C.P. Trichoderma: The genomics of opportunistic success. Nat. Rev. Microbiol. 2011, 9, 749-759. [CrossRef] [PubMed]

48. De, S.R.; Adriana, A.; Passaglia, L.M.P. Plant growth-promoting bacteria as inoculants in agricultural soils. Genet. Mol. Biol. 2015, 38, 401-419.

49. Berg, G. Plant-microbe interactions promoting plant growth and health: Perspectives for controlled use of microorganisms in agriculture. Appl. Microbiol. Biotechnol. 2009, 84, 11-18. [CrossRef] [PubMed]

50. Hermosa, R.; Viterbo, A.; Chet, I.; Monte, E. Plant-beneficial effects of trichoderma and of its genes. Microbiology 2012, 158, 17-25. [CrossRef] [PubMed]

51. Mastouri, F.; Björkman, T.; Harman, G.E. Seed treatment with Trichoderma harzianum alleviates biotic, abiotic, and physiological stresses in germinating seeds and seedlings. Phytopathology 2010, 100, 1213-1221. [CrossRef]

52. Zaidi, N.W.; Dar, M.H.; Singh, S.; Singh, U.S. Chapter 38-Trichoderma Species as Abiotic Stress Relievers in Plants. In Biotechnology \& Biology of Trichoderma; Elsevier: Amsterdam, The Netherlands, 2014; pp. 515-525.

53. Harman, G.E. Trichoderma-Not just for biocontrol anymore. Phytoparasitica 2011, 39, 103-108. [CrossRef]

54. Howell, C.R.; Hanson, L.E.; Stipanovic, R.D. Induction of terpenoid synthesis in cotton roots and control of rhizoctonia solani by seed treatments with trichodermavirens. Phytopathology 2000, 90, 248-252. [CrossRef]

55. Bal, U.; Altintas, S. Effects of Trichoderma harzianum on the yield and fruit quality of tomato plants (Lycopersicon esculentum) grown in an unheated greenhouse. Aust. J. Exp. Agric. 2006, 46, 131-136. [CrossRef]

56. Shen, Z.; Ruan, Y.; Chao, X.; Zhang, J.; Li, R.; Shen, Q. Rhizosphere microbial community manipulated by 2 years of consecutive biofertilizer application associated with banana Fusarium wilt disease suppression. Biol. Fertil. Soils 2015, 51, 553-562. [CrossRef]

57. Fu, L.; Penton, C.R.; Ruan, Y.; Shen, Z.; Xue, C.; Li, R.; Shen, Q. Inducing the rhizosphere microbiome by biofertilizer application to suppress banana Fusarium wilt disease. Soil Biol. Biochem. 2017, 104, $39-48$. [CrossRef] 
58. Xiong, W.; Guo, S.; Jousset, A.; Zhao, Q.; Shen, Q. Bio-fertilizer application induces soil suppressiveness against Fusarium wilt disease by reshaping the soil microbiome. Soil Biol. Biochem. 2017, 114, 238-247. [CrossRef]

59. Huang, X.; Chen, L.; Ran, W.; Shen, Q.; Yang, X. Trichoderma harzianum strain SQR-T37 and its bio-organic fertilizer could control Rhizoctonia solani damping-off disease in cucumber seedlings mainly by the mycoparasitism. Appl. Microbiol. Biotechnol. 2011, 91, 741-755. [CrossRef] [PubMed]

60. Casimiro, I.; Marchant, A.; Bhalerao, R.P.; Beeckman, T.; Dhooge, S.; Swarup, R.; Neil, G.; Inze, D.; Sandberg, G.; Pedro, P.J.; et al. Auxin Transport Promotes Arabidopsis Lateral Root Initiation. Plant Cell 2001, 13, 843-852. [CrossRef] [PubMed]

61. Kotasthane, A.; Agrawal, T.; Kushwah, R.; Rahatkar, O.V. In-vitro antagonism of Trichoderma spp. Against Sclerotium rolfsii and Rhizoctonia solani and their response towards growth of cucumber, bottle gourd and bitter gourd. Eur. J. Plant Pathol. 2015, 141, 523-543. [CrossRef]

62. José, L.R.; Guerrero, R.F.; Rosario, H.G.; Collado, I.G. Secondary metabolites from species of the biocontrol agent Trichoderma. Phytochem. Rev. 2008, 7, 89-123.

63. Hoagland, R.E. Toxic Metabolites of Fungal Biocontrol Agents. Fungi as Biocontrol Agents Progress Problems $\mathcal{E}$ Potential; CABI: Wallingford, UK, 2001; Volume 149, pp. 46-331.

64. Vinale, F.; Sivasithamparam, K.; Ghisalberti, E.L.; Marra, R.; Woo, S.L.; Lorito, M. Trichoderma-plant-pathogen interactions. Soil Biol. Biochem. 2008, 40,1-10. [CrossRef]

65. Vinale, F.; Sivasithamparam, K.; Ghisalberti, E.L.; Marra, R.; Barbetti, M.J.; Li, H.; Woo, S.L.; Lorito, M. A novel role for Trichoderma secondary metabolites in the interactions with plants. Physiol. Mol. Plant Pathol. 2008, 72, 80-86. [CrossRef]

66. Li, R.X.; Cai, F.; Pang, G.; Shen, Q.R.; Li, R.; Chen, W. Solubilisation of Phosphate and Micronutrients by Trichoderma harzianum and Its Relationship with the Promotion of Tomato Plant Growth. PLoS ONE 2015, 10, e0130081. [CrossRef]

67. Elkatatny, M.H. Enzyme production and nitrogen fixation by free, immobilized and coimmobillzed inoculants of Trichoderma harzianum and Azospirillum brasilense and their possible role in growth promotion of tomato. Food Technol. Biotechnol. 2010, 48, 161-174.

68. Pelagio-Flores, R.; Esparza-Reynoso, S.; Amira, G.V.; López-Bucio, J.; Alfredo, H.E. richoderma-Induced Acidification Is an Early Trigger for Changes in Arabidopsis Root Growth and Determines Fungal Phytostimulation. Front. Plant Sci. 2017, 8, 822. [CrossRef] [PubMed]

69. Lopez-Mondejar, R.; Bernal-Vicente, A.; Ros, M.; Tittarelli, F.; Canali, S.; Intrigiolo, F.; Pascual, J.A. Utilisation of citrus compost-based growing media amended with Trichoderma harzianum T-78 in Cucumis melo L. seedling production. Bioresour. Technol. 2010, 101, 3718-3723. [CrossRef] [PubMed]

70. Yedidia, I.; Srivastva, A.K.; Kapulnik, Y.; Chet, I. Effect of Trichoderma harzianum on microelement concentrations and increased growth of cucumber plants. Plant Soil 2001, 235, 235-242. [CrossRef]

71. Li, Y.T.; Hwang, S.G.; Huang, Y.M.; Huang, C.H. Effects of Trichoderma asperellum on nutrient uptake and Fusarium wilt of tomato. Crop Prot. 2017, 110, 275-282. [CrossRef]

72. Zhai, T.; Wang, Y.; Liu, Z.; Zhao, M.; Chang, Y.; Zhang, R. Trichoderma asperellum ACCC30536 inoculation improves soil nutrition and leaf artemisinin production in Artemisia annua. Acta Physiol. Plant. 2019, 41, 46. [CrossRef]

73. Yu, L.; Nicolaisen, M.; Larsen, J.; Ravnskov, S. Organic fertilization alters the community composition of root associated fungi in Pisum sativum. Soil Biol. Biochem. 2013, 58, 36-41. [CrossRef]

74. Galletti, S.; Fornasier, F.; Cianchetta, S.; Lazzeri, L. Soil incorporation of brassica materials and seed treatment with Trichoderma harzianum: Effects on melon growth and soil microbial activity. Ind. Crops Prod. 2015, 75, 73-78. [CrossRef]

75. McLean, K.L.; Dodd, S.L.; Minchin, R.F.; Ohkura, M.; Bienkowski, D.; Stewart, A. Non-target impacts of the biocontrol agent Trichoderma atroviride on plant health and soil microbial communities in two native ecosystems in New Zealand. Aust. Plant Pathol. 2013, 43, 33-45. [CrossRef]

(C) 2019 by the authors. Licensee MDPI, Basel, Switzerland. This article is an open access article distributed under the terms and conditions of the Creative Commons Attribution (CC BY) license (http://creativecommons.org/licenses/by/4.0/). 